\title{
Forest restoration assessment based on NDVI from MODIS image under different burn intensity in the burned blank in discontinuous permafrost area of Northeast China
}

\author{
Zongmei li \\ Land recourses department \\ Institute of Remote Sensing and Digital Earth Chinese \\ Academy of Sciences, University of Chinese Academy of \\ Sciences \\ Beijing, China \\ lizongmei106@163.com
}

\begin{abstract}
MODIS image, the author studies change of NDVI in different level burn intensity in burn blanks in one year and between years in discontinuous permafrost area of Northeast China. In this paper, the method based on relations of NDVI changes was set up. The study shows that the forest recovered quickly after smaller fire. And the NDVI in fire area is larger than that in no fire area.
\end{abstract}

Index Terms-NDVI changes; intra-annual and inter-annual; burn intensity.

\section{INTRODUCTION}

Fire disturbance could change the forest ecosystem. It could destroy the vegetation including the tree, the shrub, the grass and animals. Then the soil temperature, physical and chemical property would be changed [1-2].Some research showed that the fire intensity, the burned areas and frequency influenced the range of that change [3-4]. XIE fuju et al. [5] showed that the bigger of the fire intensity, the more difficult of the vegetation recovery. There was also some research which showed the forest would recover in the next five years with the help of tree planting [6].

In this study, we use NDVI from the MODIS image and study vegetation changes after fire in 2000 . We study the difference in different level fire intensity in one year and between years.

\section{STUDY AREA AND METHODS}

\section{A. study area}

The discontinuous permafrost region of northeast China covers approximately $40,000,000$ ha and is located between $46^{\circ} 40^{\prime}-53^{\circ} 30^{\prime} \mathrm{N}$ and $115^{\circ} 30^{\prime}-130^{\circ} 30^{\prime} \mathrm{E}$, with the Great Hing'an Mountains to the west, North Korea to the east, Russia to the north, and the Songnen Plain to the south (Fig. 1) This area is characterized by a cold temperate continental monsoon climate with long, cold winters and short, cool

\author{
Zengxiang zhang*, Xiaoli zhao, Xiao wang, Qingke \\ wen, Lijun zuo \\ Land recourses department \\ Institute of Remote Sensing and Digital Earth Chinese \\ Academy of Sciences \\ Beijing, China
}

summers, affected by warm, wet masses from the Pacific Ocean in the summer and continental air masses from Eurasia in the winter. The mean annual temperature is $-0.6^{\circ} \mathrm{C}$ (ranging from $-7^{\circ} \mathrm{C}$ to $6.5^{\circ} \mathrm{C}$ ), and the mean annual precipitation ranges between 345 and $660 \mathrm{~mm}$. There are more than 700 plant species in the discontinuous permafrost area. Forests are dominated by larch Larix gmelinii and birch (Betula platyphylla) [7]. Because of poor drainage in permafrost areas, many wetlands exist in the valleys. Five rivers flow through the study area and there is one lake in this area.

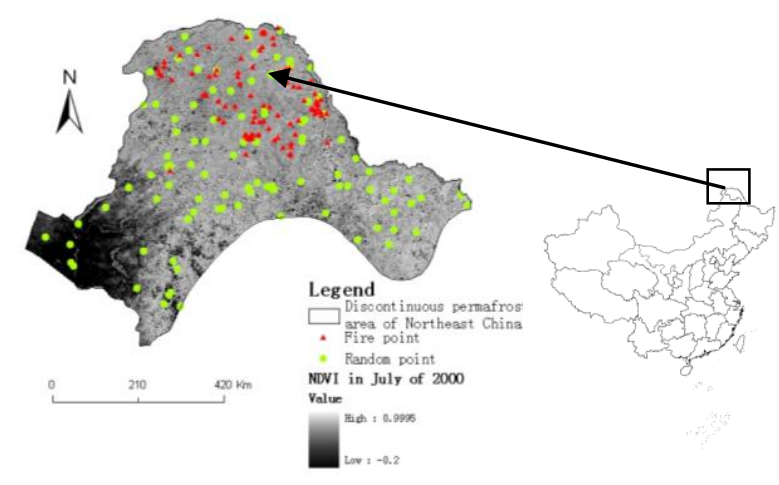

Fig.1. The study area in the discontinuous permafrost area of Northeaster China

\section{B. methods}

The NDVI is the average data. The NDVI in no fire area calculates from 100 random sample points based on ArcMap 9.3. The NDVI in fire area calculates from fire points based on ArcMap 9.3.

C. date

We use NDVI from MODIS image from 2000 to 2005. We obtain fire records for the study area from the Aviation

*Corresponding author, Emails: zx_zhang@263.net 
Forest Protection Bureau database of northeast China from 1965 to 2005.

Fire intensity is divided by the burned area. The first level forest fire is that the burned area is larger than 1000 ha. The second level forest fire is that the burned area is larger than $100 \mathrm{ha}$, and smaller than 1000 ha. The third level forest fire is that the burned area is larger than 1 ha, and smaller than 100 ha. And the forth level forest fire is that the burned area is smaller than 1 ha.

\section{RESULTS}

\section{A. Temporal changes in the fire numbers from 1965 to 2005}

Based on the analysis of the fire numbers in Northeast from 1965 to 2005 (Fig.2), it shows that the fire was most concentrate on June, and then was May from1965 to 2005. But the fire was most concentrate on May, and then was June from 1988 to 2005 . And there was no fire in January, February, November and December. So we should choose that month to study the extracting fire blanks. When we study the vegetation recovery, we should choose July and August, because the vegetation is luxuriant and temperature and precipitation is good for vegetation in those two months.

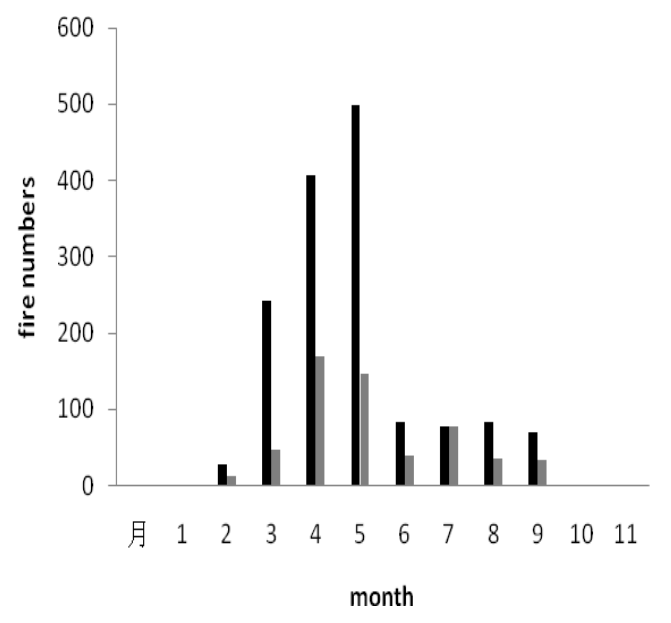

1965-2005 - 1988-2005

Fig.2. The temporal changes in the fire numbers from 1965 to 2005 and from1988 to 2005 .

\section{B. methods Temporal change in NDVI in 2000}

Based on the distribution of fire numbers in different fire intensity in Fig.3, the fire was focus on the forth level forest fire. The first and second level forest fire between 1988 and 2005 was lower than between and 1965 and 2005. The third level forest fire was drop to $1.25 \%$ from $3.70 \%$, and The first level forest fire was drop to $0.53 \%$ from $14.19 \%$. That means the management of controlling the first level forest fire is very good. There were 94 numbers of forest fires in 2000. Among that, the first level forest fire was about $2.13 \%$ and the second level forest fire was about $4.26 \%$, which was a higher proportion between 1988 and 2005. Especially, the number of the first level forest fire was 3 times between 1988 and 2005, but there are 2 times in 2000 .

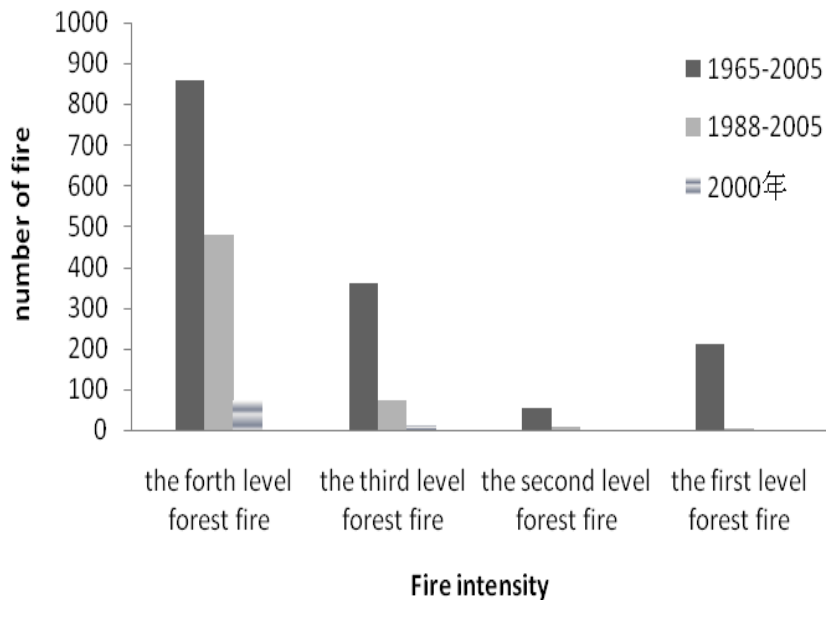

Fig.3.The numbers of fire in different level forest fire from 1965 to 2005.

We can find the NDVI temporal trend is same before September (Fig. 4). The largest NDVI was in May. The NDVI increased with the month before May. Then decreased in June and increased in July and August. After August, the NDVI was decreasing sharply. And the largest NDVI was sequence by the forth level $>$ the fire area $>$ no fire area $>$ the third $>$ the first $>$ the second. The order in July was same as that. But in August, the order was the third level $>$ the forth $>$ the fire area $>$ no fire area $>$ the first $>$ the second. That means after the fire, NDVI may be larger than before in a short time except the large fire (the second level and first level forest fire). After September, the NDVI temporal trend was different. The NDVI in no fire area was decreasing slowly. The NDVI in the first level forest fire area decreased before November, increased in December. In the other three level fire area, the NDVI decreased until October, then increase, and decreased in December.

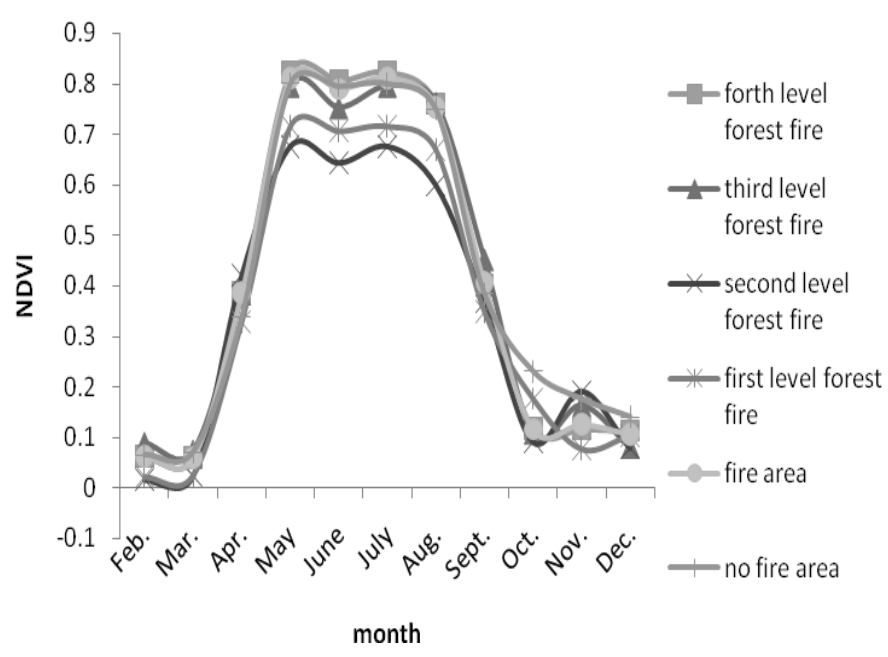

Fig. 4. The temporal intra-annual changes of NDVI in 2000.

\section{Temporal changes in NDVI from 2000 to 2005 in July and August.}

After fire, the vegetation is changed, and also the soil. So the vegetation is different recovery in the next years. So we 
choose the NDVI temporal trend in July and August to study the vegetation recovery from 2000 to 2005.

In July, the NDVI in fire area was larger than that in no fire areas (Fig.5). And the NDVI temporal trend from 2000 to 2005 was similar except in first level fire area. The NDVI in first level fire area went up from 2000 to 2003, and then decreased to 2005. The other increased from 2000 to 2001, decreased to 2003, and then increased to 2005. The NDVI in second level fire area was smallest in2003. That means the forest was changed small after the smaller fire in July.

In August, just like in July, NDVI in fire area was larger than in no fire area (Fig.5). And the temporal trends was similar except in the first level fire area and second level fire area. In the first level fire area, the NDVI was increasing until 2004. The NDVI in second level fire area was increasing from 2000 to 2001, then decreased until 2003, after that the increased in 2004 then decreased in 2005. And the other increased in 2001, decreased from 2001 to 2002, after that increased in 2003, then decreased until 2005. That means the forest recovered quickly after smaller fire. After the bigger fire, the NDVI is increasing because the grass grows up.

\section{CONCLUSIONS}

After forest fire, the plant and soil property were changed. So it is necessary to study the change of plant recovery after fire. We choose NDVI as the indicator of the plant. The fire was most concentrate on June, and then was May from1965 to 2005. But from 1988 to 2005, the fire was most concentrate on May, and then was June. The fire was focus on the forth level forest fire. The first and second level forest fire between 1988 and 2005 was lower than between and 1965 and 2005. In 2000, the NDVI temporal trend was same before September. The largest NDVI was in May. The NDVI increased with the month before May. Then decreased in June and increased in July and August. After August, the NDVI was decreasing sharply. NDVI in fire area was larger than in no fire area in July and August from 2000 to 2005 . That may be the reason that the grass recovered quickly after large fire [8]. And the temporal inter-annual trends was similar except in the first level fire area and second level fire area. The study showed that the forest recovered quickly after small fire [9].

\section{ACKNOWLEDGE}

Financial support is provided by National Project 973 "the impact of large-scale land use on global climate" - change temporal and spatial process of LUCC in China and its driving mechanism analysis during 1970s-2010(Y070090070) and the project of Young Talent Cutting-edge Special in Institute of Remote Sensing applications Chinese Academy Sciences "Simulation the impact city of three-dimensional morphology on cold bridge effect urban based on the of the high-resolution remote sensing data." We also thank all the reviewers and editors.
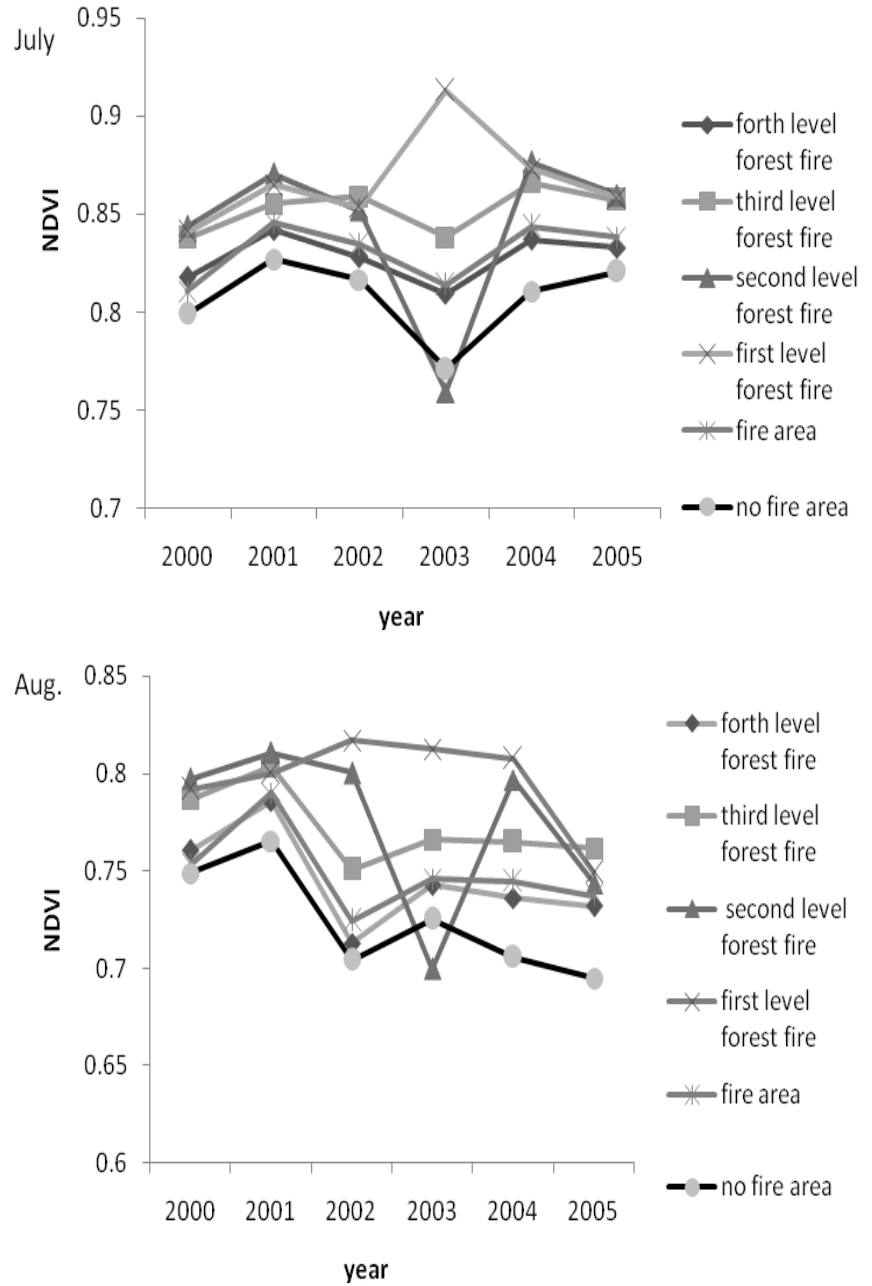

Fig. 5. The temporal inter-annual changes of NDVI from 2000 to 2005.

\section{REFERENCES}

[1]. L.B. Lentile, Z.A. Holden, A.M.S. Smith, M.J.Falkowski, A.T. Hudak, P. Morgan, S.A. Lewis, P.E. Gessler, N.C.Benson, "Remote sensing techniques to assess active fire characteristics and post-fire effects," Int. J. Wildland Fire, vol. 15, pp. 319-345, 2006.

[2]. L. Sun, J. Zhao, H.Q. Hu, "Effect of Moderate Fire Disturbance on Soil Physical and Chemical Properties of Betula platyphyllaLarix gmelinii Mixed Forest, "Scientia Silvae Sinicae, vol. 47, pp. 103-110, 2011. (in Chinese)

[3]. N. Govender, W.S.W. Trollope, B.W. Van Wilgen, "The effect of fire season, fire frequency, rainfall and management on fire intensity in savanna vegetation in South Africa," J. Appl. Ecol., vol. 43, pp.748-758, 2006.

[4]. B. Stocks, J. Mason, J. Todd, E. Bosch, B. Wotton, B .Amiro, M Flannigan, K. Hirsch, K. Logan, D. Martell, "Large forest fires in Canada, 1959-1997," J. Geophys Res, vol.107, pp.8149. 2002.

[5]. F. Xie, D.Xiao, X. Li, X.Wang, S. Xia, Y. Zhao. "Forest landscape restoration assessment based on NDVI under different burn intensity in the burned blank of Daxinganling Mountains," Chinese J. Ecol., vol.4, pp.003, 2005. (in Chinese)

[6]. J.Shatford, D. Hibbs, K. Puettmann, "Conifer regeneration after forest fire in the Klamath-Siskiyous: How much, How soon?" J. Forest.,vol.105, pp. 139-146,2007, 
[7]. J. Sun, X.Z. Li, X.W. Wang, J.J. Lv, Z.M. Li, Y.M. Hu, "Latitudinal pattern in species diversity and its response to global warming in permafrost wetlands in the Great Hing'an Mountains, China," Russ. J. Ecol+, vol. 42, pp. 123-132, 2011.

[8]. R.L. Wink, H.A. Wright, "Effects of fire on an ashe juniper community,” J Range Manag, vol. 26, pp.326-329, 2006.
[9]. D, Fox, W, Berolo, P, Carrega, F, Darboux, "Mapping erosion risk and selecting sites for simple erosion control measures after a forest fire in Mediterranean France, "Earth Surf. Proc. Land., vol. 31, pp.606-621, 2006. 